\title{
State Legislation on Smoking and Health: A Comparison of Two Policies
}

\author{
KENNETH E. WARNER \\ Department of Health Planning and Administration, School of Public Health, University of Michigan, \\ Ann Arbor, MI 48109, U.S.A.
}

\begin{abstract}
The two principal smoking-related state legislative activities stand in sharp contrast to one another. Cigarette excise taxation diffused a mong the states well before the connection between smoking and illness became a public issue, yet more recent tax increases appear to reflect a response to the national anti-smoking campaign. The growing disparity in cigarette prices between tobacco and other states has created a lucrative market in bootlegged cigarettes and has thereby brought new taxation to a virtual standstill for six years. Law's restricting smoking in public places represent a phenomenon of the 1970's clearly bearing the imprint of the anti-smoking campaign. From 1972 through 1978, the number of states with such laws in effect grew from 5 to 36, and the restrictiveness of the laws also increased. The dramatic correlation between diffusion of the laws and decreases in cigarette consumption rates seems best interpreted as each of these reflecting changes in social attitudes toward smoking.
\end{abstract}

\section{Introduction}

Public awareness of the health consequences of cigarette smoking dates from the appearance of a few articles on the subject in popular magazines in the early 1950's (e.g., Norr, 1952; Lieb, 1953; Miller and Monahan, 1954). Publication of the Surgeon General's Report on Smoking and Health in 1964 (U.S. DHEW, 1964) initiated a series of sustained if diverse efforts, often called the "anti-smoking campaign," to inform the public and encourage individuals to cease smoking, or at least to adopt less hazardous smoking behaviors. A series of major surveys demonstrates that the educational function has realized considerable success: sizable majorities of smokers and nonsmokers alike now understand both the general and specific health 
consequences of smoking, and attitudes clearly have moved in the "anti-smoking" direction (U.S. DHEW, 1969, 1973, 1976). Indicators of smoking behaviors also suggest a meaningful behavioral response: the percentage of adult Americans who smoke has fallen significantly (from $42 \%$ in 1965 to roughly a third today); annually, smokers are selecting cigarettes with lower tar and nicotine content (U.S. DHEW, 1979); and the campaign has averted anticipated increases in both the percentage of smokers and daily per-smoker consumption rates, to the point that, in the absence of the campaign, per capita cigarette consumption might have been $40 \%$ higher than it is at present (Warner, 1977 and in press).

The diversity of the efforts comprising the anti-smoking campaign is reflected in the diversity of the actors in the drama. In the private sector, the campaign has made strange bedfellows of the major voluntary societies, commercial interests peddling aids to smoking cessation (from pills to special filters to quit-smoking classes), and even the tobacco companies themselves, the latter engaging in research on less hazardous cigarettes and heavily promoting their lower tar and nicotine products.

In the public sector, governments at all levels have adopted numerous measures having the effect, direct or indirect, of restricting smoking. Most conspicuous have been the activities of the federal government in both the bureaucracy and the Congress. The latter has passed laws regulating the promotion of tobacco (e.g., package and advertisement labelling requirements and the broadcast ad ban) (Friedman, 1975), while the former has relied on publicity surrounding release of HEW reports and survey findings. Reinvigoration of the federal anti-smoking campaign occurred in January, 1978, when then-HEW Secretary Califano announced formation of the Office on Smoking and Health and an infusion of new resources into smoking research and education (Califano, 1978). Two new Surgeon General's Reports have followed, the first, released on the fifteenth anniversary of the 1964 Report, serving as a compendium of knowledge acquired over the years (U.S. DHEW, 1979), the second focusing on issues specific to smoking by women (U.S. DHEW, 1980).

The two principal smoking-related legislated activities of the states have been cigarette excise taxation, a function begun in Iowa in 1921 and performed by all of the states since 1969, and the restriction of smoking in public places ("nonsmokers' rights" laws), a relatively new concern reflected in the existence of laws on the books of 36 states as of 1978. (Prior to 1971, only five states had passed relevant laws.) Obviously, each of these policies has diffused widely, though at very different times and for quite different reasons. The purpose of this paper is to examine and compare the trends in these policies, their relationships to the anti-smoking campaign, and their effects on cigarette consumption. Washington remains the publicity center of the anti-smoking campaign, but the new "nonsmokers' rights" laws have shifted the locus of important legislative activity to the states. The influential Washington tobacco lobby and Congressional voting bloc have long constrained the development of federal smokingand-health policy (Fritchler, 1969); by contrast, state legislatures outside of the 
tobacco belt do not confront comparable tobacco interests. Hence, both political logic and current legislative activism suggest that the shift toward the states in smokingand-health initiatives may remain in force for many years to come. Given this possibility, it seems constructive to examine the nature and significance of the principal state responses to smoking to date.

The next section of this paper discusses cigarette excise taxation by the states. The following section considers the "nonsmokers' rights" movement as it is reflected in the passage of smoking-restriction legislation in the states. The concluding section compares and contrasts these two principal areas of state cigarette smoking policy [1, 2].

\section{Excise Taxation}

Historically, clearly it would be inappropriate to label cigarette excise taxation an anti-smoking policy. To be sure, many legislators may have viewed smoking as a vice which should be penalized and discouraged, but others correctly perceived a revenue potential in taxing cigarettes [3]. Beginning in 1921, the growth in the number of states taxing cigarettes followed a conventional diffusion pattern (Fig. 1) [4]. Over half of the states imposed a cigarette tax by 1940 and all but three states taxed cigarettes by 1964 , the year of the first Surgeon General's Report.

If cigarette excise taxation originally had been an anti-smoking policy, one would expect measures of early excise taxation to diverge significantly between the major tobacco-producing states (North Carolina, Kentucky, South Carolina, Virginia, Georgia, and Tennessee) and other states. Such was not the case, however. In terms of

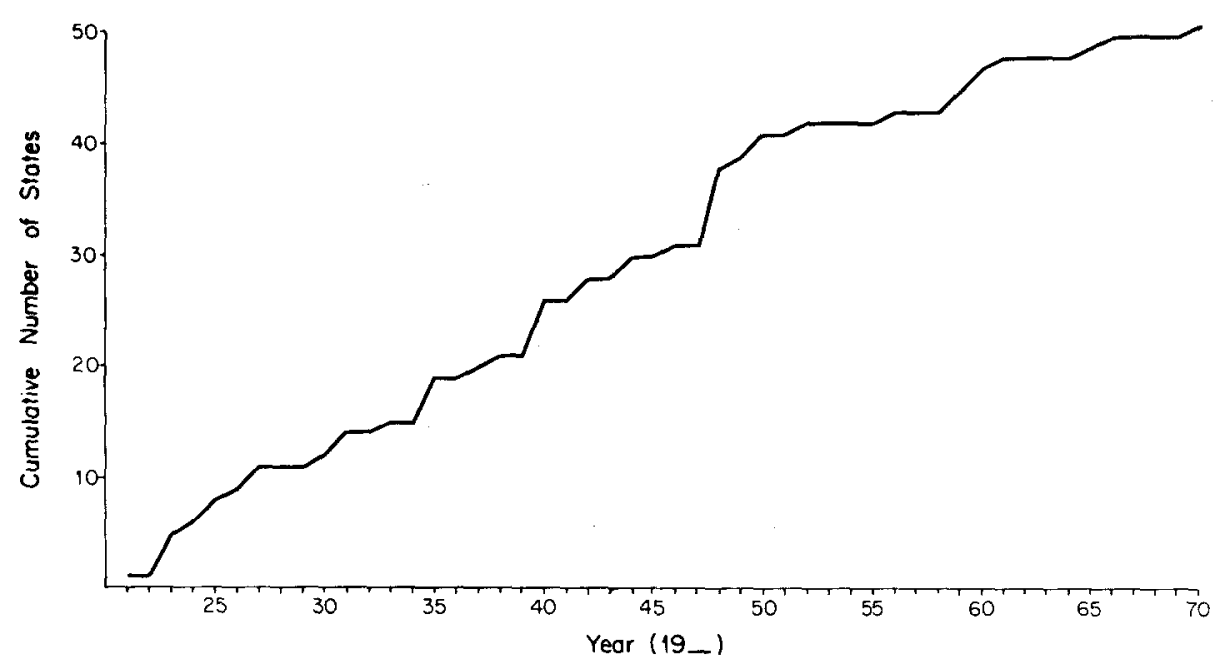

Fig. 1: Diffusion of cigarette excise taxes among the states. Source: Tobacco Tax Council, 1979, Table 4. 
the year of a state's first enactment of a cigarette tax, there is no difference between the six major tobacco states (average year $=1939)$ and the remaining states (average $=$ 1940) [5]. Similarly, prior to the first widespread publicity linking smoking to illness in the early 1950's, the average number of tax increases per state (including first enactments) was identical (equal to 1.0) for both the tobacco and other states. Finally, at that time the average rate of per-package taxation did not differ substantially between the tobacco $(2.5 \mathrm{c})$ and other states $(2.88 \mathrm{c})$.

The latter two measures began to diverge, however, as the anti-smoking campaign heated up (See Table 1). From 1953 through 1963 - from the first smoking-illness publicity to the year prior to the Surgeon General's Report - tobacco states averaged only 1.0 tax increases per state (again, including original enactments), while other states averaged 1.6. The gap widened in the post-Surgeon General's Report era, with tobacco states adding an average of 1.3 tax increases from 1964 through 1979 and other states adding double the figure, 2.6 [6]. Corresponding to this, the gap in average tax rates grew considerably. In 1963, tobacco states' taxes averaged $3.75 \mathrm{c}$ per pack (a $50 \%$ increase from the 1950 rate), while those of other states averaged $5.28 \mathrm{c}$ (an $83 \%$ increase). By 1979 , the tobacco state average was $6.75 \mathrm{c}(80 \%$ greater than in 1963$)$ and that of other states $13.58 \mathrm{c}$ (157\% higher than in 1.963$)[7,8]$.

The growth in excise taxation has not been spread out evenly over the years of the anti-smoking campaign. The nine years following issuance of the original Surgeon General's Report saw an unprecedented flurry of excise tax activity, with states averaging close to 12 excise tax increases per year (and the number of local governments imposing an excise tax rising from 225 to 378). Beginning in 1973, however, new tax legislation slowed dramatically. From that year through the end of the decade, states averaged under three increases per year. The abruptness and extent of the decrease in new state taxation may be understood more vividly by observing that in six of the nine years from 1964 through 1972, state tax increases numbered in "double figures," i.e., in excess of 10 per year, while the largest number in a later year was six (in 1978). In addition, in five of the seven years from 1973 through 1979, the

Table 1

Excise Taxation by the States

\begin{tabular}{|c|c|c|c|c|}
\hline \multirow[t]{2}{*}{ Period } & \multicolumn{2}{|c|}{$\begin{array}{l}\text { Average Number of Tax } \\
\text { Increases Per State* }\end{array}$} & \multicolumn{2}{|c|}{$\begin{array}{l}\text { Average Rate of Per-Pack } \\
\text { Taxation (end of period) (c) }\end{array}$} \\
\hline & 6 Tobacco States & Other States & 6 Tobacco States & Other States \\
\hline $1921-1952$ & 1.0 & 1.0 & 2.50 & 2.88 \\
\hline $1953-1963$ & 1.0 & 1.6 & 3.75 & 5.28 \\
\hline $1964-1979$ & 1.3 & 2.6 & 6.75 & 13.58 \\
\hline
\end{tabular}

* Includes first enactments.

Source: Tobacco Tax Council, 1979. 
Table 2

Number of States with Tax Increases (Decreases), By Year

\begin{tabular}{lrlrrl}
\hline & $\begin{array}{l}\text { No. of States with } \\
\text { Increases (Decreases) }\end{array}$ & Year & $\begin{array}{l}\text { No. of States with } \\
\text { Increases (Decreases) }\end{array}$ \\
\hline 1951 & 4 & & 1966 & 18 & \\
1952 & 4 & $(2)$ & 1967 & 4 & $(1)$ \\
1953 & 0 & 1968 & 14 & \\
1954 & 3 & 1969 & 8 & \\
1955 & 5 & 1970 & 17 & \\
1956 & 12 & 1971 & 13 \\
1957 & 3 & $(1)$ & 1972 & 13 \\
1958 & 8 & 1973 & 2 \\
1959 & 8 & 1974 & 2 \\
1960 & 13 & 1975 & 5 \\
1961 & 6 & 1976 & 2 \\
1962 & 12 & $(1)$ & 1977 & 2 \\
1963 & 9 & 1978 & 6 \\
1964 & 11 & 1979 & 1 & $(1)$ \\
1965 & 8 & & & \\
\hline
\end{tabular}

Source: Tobacco Tax Council, 1979, Table 7.

number of increases equaled only one or two. Prior to 1973, one has to go back 20 years to 1953 to find a year with fewer than three increases (See Table 2).

The principal reason for the deceleration in the rate of tax increases appears to have been recognition that interstate cigarette bootlegging was becoming a problem of considerable magnitude (Advisory Commission on Intergovernmental Relations, 1977). Differences in state tax rates account for almost all of the variation in cigarette retail prices among the states. Prices of cigarettes in the lowest-tax states (North Carolina, Virginia, and Kentucky each impose a state tax of from 2-3 cents per pack of cigarettes) run more than 20 cents less per pack than those of the highest-tax states [9]. It has been estimated that a single truckload of bootlegged cigarettes can generate $\$ 20,000$ or more in smuggling profits (The Washington Post, 1978). Overall, high-tax states are estimated to lose from $\$ 400$ to $\$ 500$ million in tax revenues each year due to bootlegging (The Economist, 1978; Advisory Commission, 1977). The consequence, of course, is that state legislatures are unwilling to raise excise taxes and thereby increase the smuggling-inducing price differential. In fact, discussion of tax decreases has occurred in certain high-tax states, the assumption being that a lowered differential would decrease bootlegging sufficiently to outweigh the smaller tax rate, and hence that tax revenues would increase [10].

Regardless of the reasons for fluctuations in tax-increase legislative activity, the changes undoubtedly have influenced cigarette consumption rates. Demand for cigarettes is price-inelastic but the elasticity is nonzero; that is, changes in real cigarette prices will affect aggregate consumption. Given that cigarette production generally is 
considered a constant-cost industry, real changes in cigarette price are largely attributable to changes in tax rates. Hence the fluctuations in state tax trends can be translated into probable consumption impacts by estimating changes in demand attributable to real price changes. Elsewhere, I have attempted this (Warner, in press). I concluded that the rapid growth in taxation through 1972 served to depress growth in cigarette consumption, while the post-1972 near-cessation in new taxation, which lowered the real price of cigarettes [11], should have stimulated consumption.

Numerically, I estimated that by 1972 , adult per capita cigarette consumption, which then totaled 4115 , would have been higher by over 630 cigarettes $(15 \%)$ had cigarette prices (i.e., taxes) increased only at the general rate of inflation. By comparison, the consumption-depressing effects of anti-smoking publicity per se totaled only slightly over 400 cigarettes per capita ( $10 \%$ of actual consumption). In 1978, however, the rapid growth of tax increases through 1972, then the rapid deceleration for the remainder of the decade, had shrunk the net effect of price changes to 200 cigarettes per capita, or only $5 \%$ of that year's actual consumption rate of 3889 . Again by comparison, anti-smoking publicity accounted for a consumption decrease

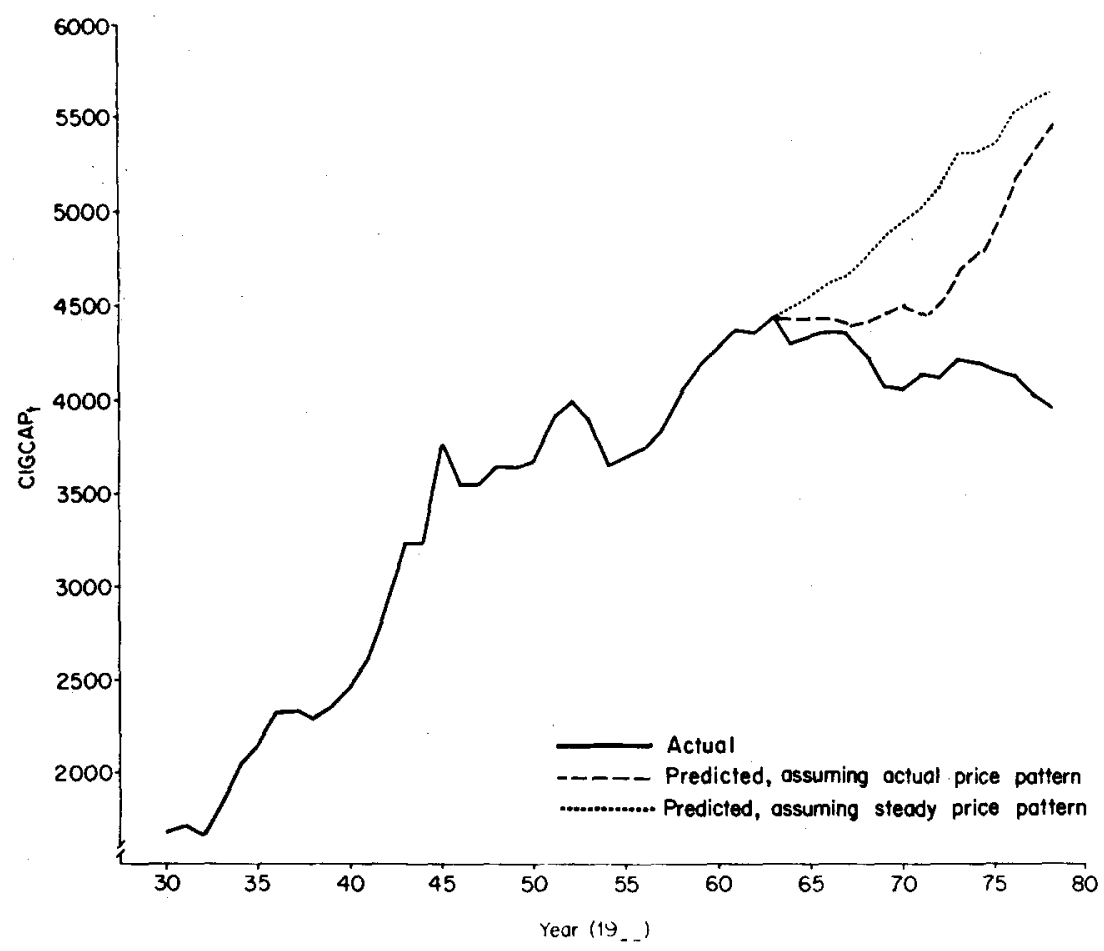

Fig. 2: Adult per capita cigarette consumption, actual and predicted in absence of anti-smoking campaign. Source: Warner (1980). 
of 1450 cigarettes per capita, well over a third of the actual rate. In other words, by the end of the decade, anti-smoking era fluctuations in cigarette tax and price trends had only a minor influence on cigarette consumption, but that minor influence reflected the averaging of a considerable depressing impact through the 1960's and early 1970's and a significant consumption-inducing effect through the remainder of the decade of the 1970's [12].

Fig. 2 illustrates the effects of the price fluctuations for the years following the 1964 Surgeon General's Report. The solid line traces actual annual adult per capita cigarette consumption ( $\mathrm{CIGCAP}_{t}$ ). The middle (dashed) line traces the per capita consumption path which would have been expected in the absence of the anti-smoking publicity, but assuming that the actual pattern of taxation (and hence prices) would have occurred even though the anti-smoking publicity had not. The top (dotted) line estimates the consumption path expected in the absence of the campaign, but now assuming that the relative cigarette price did not change much from its 1963 level. That is, I have attributed the rapid growth in taxation from 1964-1972 to the campaign and have assumed that, in the absence of the campaign, a steady pattern of tax increases (and prices) would have been realized. Thus, the gap between the two top lines represents an estimate of the consumption-depressing effects of campaign-induced taxation.

In summation, state excise taxation of cigarettes - obviously a potential weapon in the anti-smoking effort - arose in an era which was not especially hostile toward smoking. More recent differences between tobacco and other states in tax-increase activity do seem consistent with a growing concern about the hazards of smoking, but the evidence cannot be considered definitive that states view taxation as an appropriate and effective weapon against smoking. To some extent, the problem of interstate bootlegging has made the issue moot; new state tax increases have been few in number since 1972, and anti-bootlegging tax decreases have been under consideration in high-tax states.

Regardless of the motivation for states' increasing taxes, the activity clearly has had an impact on cigarette comsumption rates. Through 1972, rapid increases in state taxes had a significant depressing effect on consumption, while the recent moratorium on tax increases has decreased the real relative price of cigarettes and thereby created an inducement for more smoking to occur. Indeed, the steady decrease in per capita cigarette consumption since the early 1970's is particularly impressive in light of this economic incentive for smoking to increase (Warner, 1981).

\section{“Nonsmokers' Rights” Laws: The Restriction of Smoking in Public Places}

The second major area of smoking-related state legislative activity - passage of "nonsmokers' rights" laws - stands in striking contrast to excise taxation in several dimensions: timing, motivation and effect. While excise taxation flourished before the smoking-and-health issue arose, nonsmokers' rights legislation is a phenomenon of 
the 1970's; indeed, the diffusion of such legislation among the states "took off" only when new excise taxation activity had leveled off in the early 1970's. Recent laws restricting smoking in public places bear a distinctive "anti-smoking" or "nonsmokers" rights" imprint, while the motivation underlying tax increases is more of a mixed bag. Finally, regardless of their motivation, tax increases (or their absence) can be identified with impacts on cigarette consumption rates, but the effects of the new restrictive laws on smoking behavior remain a subject of conjecture. Indeed, as is discussed below, there is some reason ro believe that the new laws are reflecting behavior change, rather than producing it.

State-legislated restrictions on smoking in public places are not exclusively a legislative innovation of the 1970's, but the number and restrictiveness of pre-1970 laws are surprisingly limited. Vermont put the first such law on the books in 1892, prohibiting smoking in any place in which the owner, agent, occupant, or custodian had posted no-smoking signs. Smoking-restriction legislation "diffused" to Vermont's neighbor, New Hampshire, 57 years later (1949) when the Granite State restricted smoking in public transportation. Five years passed (1954) before a third New

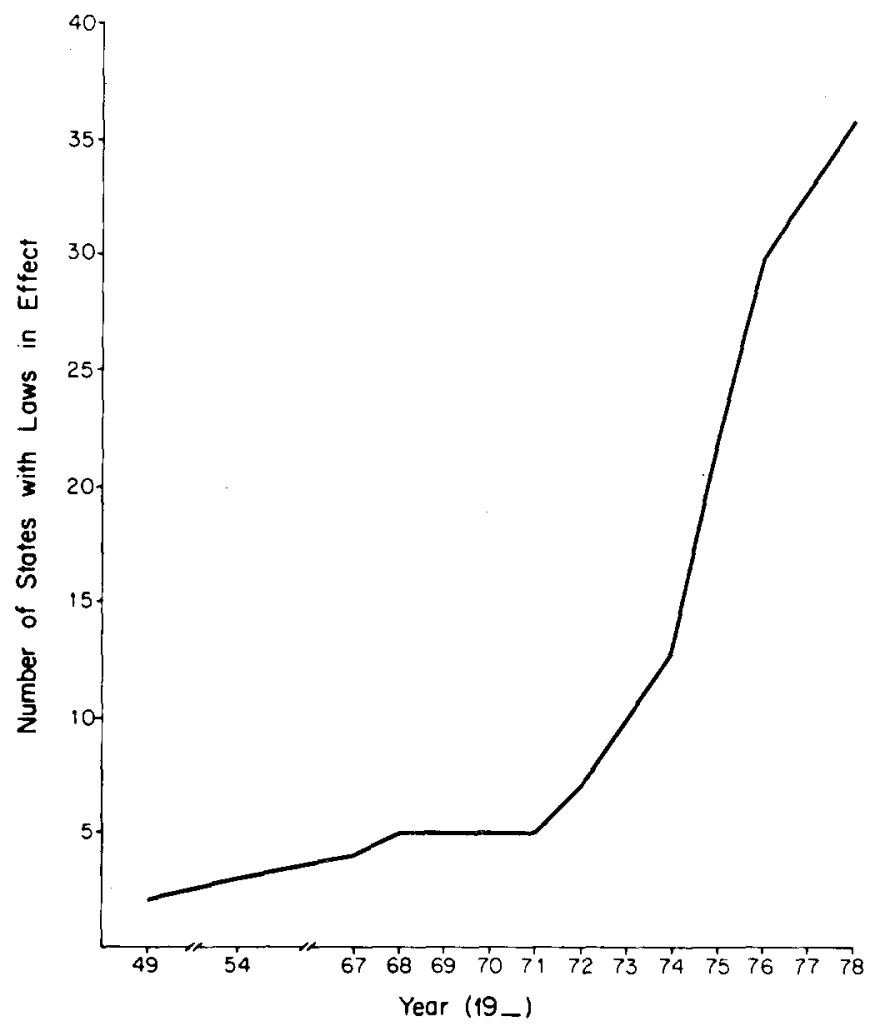

Fig. 3: Diffusion among the states of legislated restrictions on smoking in public places.

Sources: Unpublished data supplied by the Tobacco Merchants Association and the Tobacco Institute. 
England state, Maine, joined the ranks. Only two other states passed relevant legislation in nearly two decades dating from the first public discussion of the connection between smoking and illness: in 1967, Michigan became the first state outside of New England to pass smoking-restriction legislation, and that law only prohibited smoking in elevators; a year later, Massachusetts became the fourth New England state to put smoking restriction on the books, with a law relating to smoking in public transportation.

Despite this slow start, smoking-restriction legislation diffused rapidly through the 1970 's. Beginning in 1972, the number of states with relevant legislation in effect grew to 36 by the end of 1978; nine, followed by eight new states joined the ranks in 1975 and 1976, respectively. As a consequence, the U.S. adult population residing in states with smoking-restriction laws rose from $8.1 \%$ in 1971 to $72.3 \%$ in 1978 . As with excise taxation, the diffusion pattern is the conventional S-shaped one [13] (See Fig. 3).

In addition to the simple diffusion of states with legislation, the restrictiveness of laws passed grew over time [14]. All of the five pre-1970's laws were only minimally restrictive. Of 13 laws passed from 1972 through 1974, eight were minimally restrictive, five moderately restrictive, and none highly restrictive. By contrast, of 37 new laws dating from 1975 through 1978, 10 were minimally restrictive, 17 moderately restrictive, and 10 highly restrictive. Table 3 presents data on the diffusion of new laws over time and the average restrictiveness per law per year.

That smoking-restriction laws should be associated with the anti-smoking campaign is beyond question. A principal concern, perhaps the major theme, of the

Table 3

New Annual State Smoking-Restriction LegislationNumber and Average Restrictiveness

\begin{tabular}{lrl}
\hline Year(s) & No. of new laws & $\begin{array}{l}\text { Average } \\
\text { Restrictiveness* }\end{array}$ \\
\hline $1892-1971$ & 5 & 0.33 \\
1972 & 3 & 0.33 \\
1973 & 3 & 0.44 \\
1974 & 7 & 0.52 \\
1975 & 17 & 0.65 \\
1976 & 5 & 0.60 \\
1977 & 11 & 0.76 \\
1978 & 4 & 0.67 \\
\hline
\end{tabular}

* The restrictiveness weights were set arbitrarily as follows: minimally restrictive $=0.33$, moderately restrictive $=0.67$, and highly restrictive $=1.00$.

Sources: Unpublished data supplied by the Tobacco Merchants Association and the Tobacco Institute and author's calculations. 
campaign in the 1970's was the protection of the rights of nonsmokers [15]. In the early half of the decade, this concern arose in large part from evidence that "second-hand", "involuntary", or "passive" smoking - inhalation by nonsmokers of the smoke from smokers' cigarettes - could be hazardous to the health of non-smokers; hence the push for legislation restricting smoking in public places. In more recent years, the physical health hazards of passive smoking were deemphasized - some evidence suggested that those hazards were serious only for individuals with significant allergies, respiratory and circulatory problems and the like (U.S. DHEW, 1979) - and the nonsmokers' rights movement took on more of an ethical tone: the question became, "simply", one of whose rights to clean air - smokers' or nonsmokers' - should dominate (Axel-Lute, 1978). New evidence linking regular passive smoking to physical impairment comparable to that of light smokers may reintroduce the health-effects theme (White and Froeb, 1980).

The link between support of nonsmokers' rights and passage of state laws is logical, clear and direct. It is reflected in the fact that by the end of 1978 only two of the six tobacco states $(33 \%)$ had passed any smoking-restriction legislation, while 34 of the 45 other states $(75 \%)$ had such legislation on the books $[16,17]$.

Ostensibly, the purpose behind the nonsmokers' rights laws was not to reduce the amount of smoking per se, but rather to protect nonsmokers from the irritation of involuntary exposure to smoke. Nevertheless, one might expect that smokingrestriction laws, particularly the highly restrictive ones, would force a reduction in total cigarette consumption, simply because smokers would be prohibited from smoking in unavoidable designated places. Unfortunately, analysis of this phenomenon has been extremely limited to date. One study comparing states' consumption rates did not identify an impact (Bloom, 1979) and my own aggregate time series study proved inadequate to the analytical task (Warner, 1981). The question may never be resolved, though other state cross-sectional analyses or disaggregated microeconomic consumption survey studies might identify such an effect.

It is interesting, however, to note the high correlation between the growth in smoking-restriction legislation in the aggregate and the recent national decline in per capita consumption rates (Warner, 1981). The latter has occurred in each of the last six years, the first time in the century that per capita consumption fell more than three consecutive years [18]. The correlation between legislation growth and consumption decline is so great that it is not logical to attribute the latter to the physical and temporal barriers to smoking imposed by the laws. Rather, my interpretation of the correlation is that the consumption declines reflect a behavioral response to the entirety of the anti-smoking campaign, a response which has lagged knowledge and attitudinal changes by several years (U.S. DHEW 1969, 1973, 1976). Growth in the legislation serves simply as a good gauge of a growing public nonsmoking sentiment in general and, in particular, political activism by advocates of nonsmokers' rights. In short, passage of the laws seems to be a reflection of social values, rather than a creator of them [19]. 


\section{Conclusion}

The two principal state legislative activities relating to smoking and health stand in sharp contrast to one another. The one which clearly seems to have affected cigarette consumption - excise taxation - was not intended originally to serve as an antismoking weapon. Ironically, its more enthusiastic application in the nontobacco states in the early years of the national anti-smoking campaign, possibly as an anti-smoking tactic, helped to create the large price disparities among states which have promoted a lucrative trade in interstate cigarette smuggling. Such bootlegging has contributed to a rapid drop in the rate of new excise taxation in recent years. Consequently real relative cigarette prices have fallen continuously since 1972 . While a variety of educational and publicity efforts is directed at reducing smoking, decline in this basic economic variable serves to encourage smoking. This may be particularly true among groups such as the young and poor, who seem most responsive to the direct cost of smoking.

By contrast, the profusion of state smoking-restrition laws reflects the direct political activism of anti-smoking forces. A phenomenon of the 1970's, such laws legislate the protection, and the rights, of nonsmokers. But they may very well result from, rather than direct, the social milieu regarding smoking. The consumption impact of smoking-restriction laws remains to be established, but it seems plausible that their direct impact will remain small compared to that of their legislative predecessors.

Regardless of the laws' direct effects on consumption, their number, variety, and increasingly comprehensive coverage emphasize the potential for anti-smoking legislative activity at the state level. For both the present and the foreseeable future, political factors will severely constrain such activity at the federal level. Thus, if new types of smoking-related legislation are to emerge, the states seem a likely forum and the nonsmokers' rights movement a likely model for their evolution and diffusion.

\section{Acknowledgments}

This is a revised version of a paper presented at the annual meeting of the Western Political Science Association, San Francisco, March 28, 1980. My colleague, James Chesney, provided helpful comments on an earlier draft. Farrell Delman of the Tobacco Merchants Association supplied much useful information and data on the state laws, as did the Tobacco Institute. The project was supported by Grant Number HS 03634 from the National Center for Health Services Research, OASH. I am also grateful for the support of the Kellogg Foundation through its National Fellowship Program. 


\section{Notes}

1 Emphasis is placed on the word "principal" because most states also have other smoking-related policies on their books. For example, the vast majority of states require some health education on smoking in all school districts (American School Health Association, 1979). Most such requirements are vague in their definition and often extremely limited in their implementation. A few states are attempting to evolve more comprehensive policy approaches to smoking. For example, in Michigan a Citizens' Panel on Smoking and Health, appointed by the Governor, has developed a package of policy recommendations for implementation in the State.

2 While this paper will focus on state policies, it should be emphasized that numerous local governments have adopted policies of their own. For example, in 1979, 348 cities and 17 counties imposed excise taxes on cigarettes. Note, however, that all but 27 of these local taxes were concentrated in two states, Alabama and Missouri, with the remaining 27 scattered among five other states (see Table 16, Tobacco Tax Council, 1979). Concerning the restriction of smoking in public places, scores of local governments have relevant ordinances in effect.

3 Virtually all empirical studies of the demand for cigarettes have found that demand is price inelastic, with a "consensus" estimate of elasticity in the vicinity of -0.4 to -0.5 (Lyon and Spruill, 1977; Coate and Lewit, 1980). This means that a $10 \%$ increases in price would decrease demand 4-5\%. Hence increase in tax rates can be expected to increase tax revenues.

4 While the shape of the interstate diffusion pattern was conventional, the order in which states adopted the cigarette excise tax did not follow the general pattern of "innovativeness" among the states. I regressed the date of a state's first enactment of an excise tax against Walker's calculation of the state's "composite innovation score" (Walker, 1969, Table 1) and found no significant relationship; indeed, there was a small but near-significant correlation in the theoretically wrong direction.

5. Ironically, if one excludes the last state to adopt a cigarette excise tax, North Carolina, the average year of enactment of the remaining five tobacco states, 1933, falls considerably earlier than the average of all other states.

6 Since 1950, the six tobacco states have also legislated four tax decreases, compared with only three for the other 45 states (including the District of Columbia).

7 Due to the small total number of tax laws, neither the change in differences in numbers of tax increases or tax rates is statistically significant. However, the numbers are certainly consistent with theoretical expectations and can be viewed as suggestive evidence.

8 It is interesting to observe that the federal cigarette per-pack excise tax has not changed from $8 \mathrm{c}$ since 1952. As a consequence, the federal tax share of average retail price has dropped during that period from over $35 \%$ to $13 \%$. Failure of the federal tax to increase is a reflection of the aforementioned strength of the tobacco presence in Washington politics.

9 Connecticut, Florida and Massachusetts impose a 21 -cent per-package tax, with retail price averaging 67-70 cents. A few other states have lower state taxes but equally high retail prices due to municipal taxes. Most notable is New York, in which a state tax of 15 cents is supplemented in New York City by a municipal tax which generated over $\$ 63$ million in 1979 (Tobacco Tax Council, 1979).

10 It is interesting to speculate on the effects of inflation on smuggling in recent years. General price inflation has decreased the real value of the differential between high-and low-tax states, while the rising cost of fuel has increased the cost of bootlegging. If bootlegging had reached its equilibrium level a few years ago, inflation should have decreased the amount of bootlegging. There are no data available to address this question directly, but states identified as the major victims of bootlegging in the mid-1970's (Advisory Commission on Intergovernmental Relations, 1977) have experienced relatively greater revenue growth than the states benefiting from bootlegging (comparing states with no tax rate changes). This is suggestive of a decrease in smuggling activity.

$1 \mathrm{I}$ The price of cigarettes is a function of the costs of production and distribution and taxes. If production and distribution costs rise at a rate consistent with other prices (i.e., average inflation) but taxes do not increase, the net effect is a decrease in the price of cigarettes relative to the general price level. An index of real cigarette price - i.e., the price of cigarettes relative to the general consumer price level (with the index set equal to 100 in 1967) - rose from 92.70 in 1963 to 107.98 in 1972 and then fell rapidly to 92.02 in 1978 . 
12 All of these estimates are based on a price elasticity of demand of -0.37 , estimated at the means of dependent and independent variables in the regression analysis reported in my recent paper (Warner, 1981). Obviously, lower or higher elasticity estimates would alter the number, but the qualitative story would not be affected.

13 Unlike excise taxation, the order (date) in which states adopted smoking-restriction legislation did correlate significantly ( $p=0.01)$ with Walker's "composite innovation scores" for the states. That is, the early adopters of smoking-restriction legislation tended to be the more legislatively innovative states in general (Walker, 1969). Note, however, that this conclusion is statistically sensitive to the treatment of early adopters and nonadopters. In order not to weight unduly the positions of Vermont and the other four pre-1970 adopters, each of these five states was arbitrarily assigned a "starting" date of 1971, the year before any other states implemented relevant legislation. Similarly, in order to include nonadopters, they were assigned an "adoption date" of 1980 . When both the nonadopters and very early adopters were excluded from the analysis, the significant correlation disappeared.

14 Determination of the restrictiveness of a law required subjective judgments. In general, laws were rated as minimally restrictive if they refer to only a limited number of sites in which people spend relatively little time (e.g., elevators or public transportation). By contrast, a highly restrictive law is one with broad coverage and/or inclusion of sites populated by large numbers of people for significant periods of time (e.g., work places, public buildings, stores).

While the classification of individual laws is subjective, $I$ attempted a classification by myself and then compared my results with those prepared by the Tobacco Merchants Association (Bloom, 1979). In the few instances in which discrepancies existed, I discussed them with an analyst at the Association and, when appropriate, adjusted my classification. Despite the subjectivity of the process, our classifications were remarkably consistent.

It should be emphasized that "restrictiveness" is assessed independent of enforcement. Few of the laws are vigorously enforced. Most states rely on voluntary compliance resulting from social pressure and general "good citizenship".

15 In the 1960's, the principal concern was paternalistic in nature: protecting smokers from their own bad habits.

16 If one separates out the six other states which account for almost all tobacco production not attributable to the "big six" states, the percentage rises to $82 \%$. Indiana and Wisconsin, two of the "little six" (the others being Florida, Maryland, Ohio and Connecticut), had no relevant laws on the books as of the end of 1978 .

17 The issue of nonsmokers' rights to clean air has received its greatest national visibility, if not always success, through recent ballot initiatives, especially those in California and Florida's Dade County.

18 The three-year decline coincided with the Fairness Doctrine "equal-time" anti-smoking messages broadcast on television and radio from 1968 through 1970. There is a fair amount of evidence causally linking the consumption declines to the broadcast messages (Warner, 1979).

19 Conceptually, this ought to be empirically testable by comparing correlations reflecting different lags or leads. Unfortunately, the mechanism is quite complex. If both smoking and legislative behavior changes lag attitudinal changes, but not necessarily at the same rate, how does one interpret legislative growth leading consumption decline? Is the former causing the latter or does the former lag attitudinal changes less long than behavioral changes? What if there is a symbiotic relationship between attitudes and legislation or legislation and smoking behavior? My attempts at untangling this empirically have proved fruitless.

\section{References}

Advisory Commission on Intergovernmental Relations (1977). Cigarette Bootlegging: A State and Federal Responsibility: Washington: ACIR.

American School Health Association (1979). Smoking and Health in America-A Survey of State School Health Programs, 2nd ed. Atlanta: Center for Disease Control.

Axel-Lute, P. (1978). "Legislation against smoking pollution," Environmental Affairs 6: 345-371. 
Bloom, M. (1979). "Restrictions on Smoking: Observations on Their Impact." Presented at the 28th Tobacco Workers' Conference, Orlando, Fla., Jan. 18.

Califano, J. (1978). Address delivered to the National Interagency Council on Smoking and Health, Jan. 11.

Coate, D. and Lewit, E. (1980). "The Potential for Reducing Cigarette Smoking through the Use of Excise

Taxes." Presented at the Annual Meeting of the American Economics Association, Denver, September 5.

The Economist (1978) "Cigarette Contraband" Mar. 11, p. 42.

Friedman, K. (1975). Public Policy and the Smoking - Health Controversy. Lexington, Mass.: D.C. Heath. Fritchler, A. (1969). Smoking and Politics: Policlmaking and the Federal Bureaucracy. New York: Appleton-Century-Crofts.

Lieb, C. (1953). "Can the poisons in cigarettes be avoided?," Reader's Digest 63. (December): 45-47.

Lyon, H. and Spruill, M. (1977). "A Temporal Cross-Section Analysis of Cigarette Price Elasticity in the United States." Working Paper, Univ. of Houston.

Miller, L. and Monahan, J. (1954). "The Facts Behind the Cigarette Controversy," Reader's Digest 65 (July): 1-6.

Norr, R. (1952). "Cancer by the Carton," Reader's Digest 61 (December): 7-8.

Tobacco Tax Council (1979). The Tax Burden on Tobacco: Historical Compilation. Richmond, Va.

U.S. DHEW, Public Health Service (1964). Smoking and Health: Report of the Advisory Committee to the Surgeon General of the Public Health Service. Washington: U.S. Government Printing Office.

U.S. DHEW, Public Health Service (1969). Use of Tobac'o: Practices, Attitudes, Knowledge, and Beliefs, United States - Fall 1964 and Spring 1966. Washington: U.S. Government Printing Office.

U.S. DHEW, Public Health Service (1973). Adult Use of Tobacco - 1970. Atlanta: Center for Disease Control.

U.S. DHEW, Public Health Service (1976). Adult Use of Tobacco - 1975. Atlanta: Center for Disease Control.

U.S. DHEW, Public Health Service (1979). Smoking and Health - A Report of the Surgeon General. Washington: U.S. Government Printing Office.

U.S. DHEW, Public Health Service (1980). The Health Consequences of Smoking for Women-A Report of the Surgeon General. Washington: U.S. Government Printing Office.

Walker, J. (1969). "The diffusion of innovations among the American states," Amer. Pol. Sci. Rev. 63: 880-899.

Warner, K. (1977). "The effects of the anti-smoking campaign on cigarette consumption," Amer. J. Pub. Hith 67: 645-650.

Warner, K. (1979). "Clearing the airwaves: The cigarette ad ban revisited," Policy Analysis 5: 435-450.

Warner, K. (1981). "Cigarette smoking in the seventies: The impact of the anti-smoking campaign on consumption," Science (in press).

The Washington Post (1978). "Bootleg cigarettes," Oct. 17.

White, J. and Froeb, H. (1980). "Small-airways dysfunction in nonsmokers chronically exposed to tobacco smoke," New' Engl. J. Med. 302: 720-723. 